\title{
Distinctive Profiles of Gene Expression in the Human Nucleus Accumbens Associated with Cocaine and Heroin Abuse
}

\author{
Dawn N Albertson 1,5, Carl J Schmidt ${ }^{2}$, Gregory Kapatos ${ }^{1,3,4}$ and Michael J Bannon*,1,3,4 \\ 'Department of Psychiatry \& Behavioral Neurosciences, Wayne State University School of Medicine, Detroit, MI, USA; '2 Department of Pathology, \\ Wayne State University School of Medicine, Detroit, MI, USA; ${ }^{3}$ Department of Pharmacology, Wayne State University School of Medicine, \\ Detroit, MI, USA; ${ }^{4}$ Center for Molecular Medicine \& Genetics, Wayne State University School of Medicine, Detroit, MI, USA
}

\begin{abstract}
Drug abuse is thought to induce long-term cellular and behavioral adaptations as a result of alterations in gene expression. Understanding the molecular consequences of addiction may contribute to the development of better treatment strategies. This study utilized highthroughput Affymetrix microarrays to identify gene expression changes in the post-mortem nucleus accumbens of chronic heroin abusers. These data were analyzed independently and in relation to our previously reported data involving human cocaine abusers, in order to determine which expression changes were drug specific and which may be common to the phenomenon of addiction. A significant decrease in the expression of numerous genes encoding proteins involved in presynaptic release of neurotransmitter was seen in heroin abusers, a finding not seen in the cocaine-abusing cohort. Conversely, the striking decrease in myelin-related genes observed in cocaine abusers was not evident in our cohort of heroin subjects. Overall, little overlap in gene expression profiles was seen between the two drug-abusing cohorts: out of the approximately 39000 transcripts investigated, the abundance of only 25 was significantly changed in both cocaine and heroin abusers, with nearly one-half of these being altered in opposite directions. These data suggest that the profiles of nucleus accumbens gene expression associated with chronic heroin or cocaine abuse are largely unique, despite what are thought to be common effects of these drugs on dopamine neurotransmission in this brain region. A re-examination of our current assumptions about the commonality of molecular mechanisms associated with substance abuse seems warranted.

Neuropsychopharmacology (2006) 3 I, 2304-2312. doi:I 0.1038/s..npp. I 301089; published online 3 May 2006
\end{abstract}

Keywords: human; post-mortem; nucleus accumbens; heroin; microarray; cocaine

\section{INTRODUCTION}

Although drug abuse and addiction has been studied extensively for decades, the underlying molecular mechanisms are still not well understood. The contributions of animal models to our understanding of drug abuse are undeniable but, at the same time, many features of human drug addiction (eg spontaneous drug self-administration, and the pattern and length of drug use) are difficult, if not impossible, to recapitulate in experimental models. Fortunately, the human post-mortem brain is amenable to neurochemical analysis, providing a complementary strategy for examining the effects of drug abuse at a molecular level in human drug addicts. The advent of high-throughput micro-

*Correspondence: Dr MJ Bannon, Department of Pharmacology, Wayne State University School of Medicine, 2309 Scott Hall, 540 E. Canfield Avenue, Detroit, MI 4820I, USA, Tel: + I 313993 427I,

Fax: + | 313993 4269, E-mail: mbannon@med.wayne.edu

${ }^{5}$ Current address: Department of Psychology, Minnesota State University, Mankato, MN, USA

Received 13 July 2005; revised 17 March 2006; accepted 22 March 2006

Online publication: 28 March 2006 at http://www.acnp.org/citations/ Npp032806050454/default.pdf array technology enables investigators to simultaneously examine changes in gene expression across hundreds of genes or even entire genomes. In the last several years, microarray analysis of post-mortem brain has been successfully applied to the study of gene expression in the human drug abuser (Albertson et al, 2004; Bannon et al, 2005; Lehrmann et al, 2003; Lewohl et al, 2000; Mayfield et al, 2002; Tang et al, 2003). Such studies are likely to increase our understanding of the consequences and complexities of addiction.

In a previous microarray study investigating gene expression changes in the nucleus accumbens of human cocaine abusers, we identified a striking downregulation of numerous myelin-related genes (Albertson et al, 2004). The decreased myelin basic protein (MBP), proteolipid protein (PLP), and myelin-associated oligodendrocyte basic protein (MOBP) gene expression seen in cocaine abusers (Albertson et al, 2004; Bannon et al, 2005; Lehrmann et al, 2003; Tang et al, 2003) may be a molecular correlate of white matter changes identified through neuroimaging studies (Bartzokis et al, 2002; Bartzokis et al, 1999b; Bartzokis et al, 1999a; Chang et al, 1997; Chang et al, 1999; Lim et al, 2002). We have posited (Albertson et al, 2004) that the excessive extracellular levels of the neurotransmitter dopamine induced by cocaine abuse may retard the conversion of immature 
oligodendrocytes into mature myelin-producing cells, a process thought to be dopamine-sensitive (Bongarzone et al, 1998; Howard et al, 1998). If this hypothesis is correct, then similar changes in myelin gene expression should be seen in the nucleus accumbens of abusers of other illicit drugs known to increase extracellular dopamine levels. Heroin, through the activation of $\mu$ opioid receptors located on inhibitory GABAergic interneurons in the midbrain, disinhibits mesolimbic dopamine neurons and may elicit increased levels of extracellular dopamine in the nucleus accumbens (Wise et al, 1995; Xi et al, 1998). The recent resurgence of heroin abuse and its effects on nucleus accumbens dopamine make heroin-abusing subjects a potentially important cohort for post-mortem analysis of gene expression and comparison to cocaine abusers.

In the present study, we employed high-throughput microarray technology to identify gene expression changes in the nucleus accumbens of chronic heroin abusers. To our knowledge, this is the first such analysis reported. Data were analyzed independently and in relation to our previously reported study on human cocaine abusers in an effort to determine which alterations in gene expression are drug specific and which may be common to many or all drug addictions.

\section{MATERIALS AND METHODS}

\section{Cocaine Study}

A portion of the cocaine-related microarray data set has been previously described (Albertson et al, 2004; Bannon et al, 2005). Briefly, RNA from the nucleus accumbens of 10 cocaine abusers and 10 matched controls (listed in Table 1) were hybridized to Affymetrix u133A and u133B microarrays and data were analyzed in pairs using a Wilcoxon signed rank test $(p \leqslant 0.05)$. For a transcript to be considered significantly different between groups, it had to be present in all samples and changed in the same direction in the majority of pairs ( $\geqslant 6$ out of 10 pairs).

\section{Tissue Acquisition and Subject Characterization}

For this study, brain specimens were collected as part of the routine autopsy process under a protocol approved by Wayne State University's Human Investigation Committee, as previously described (Albertson et al, 2004; Bannon et al, 2005). Heroin users $(n=7)$ exhibited a positive blood toxicology for heroin and/or its metabolites (eg 6-monoacetyl morphine, morphine, morphine glucuronide). Control subjects $(n=7)$ were matched pairwise with heroin users for gender, race, age, and brain $\mathrm{pH}$ (Table 1). Of the 14 subjects, one control and two heroin subjects tested positive for moderate levels of alcohol $(\leqslant 0.11 \mathrm{~g} / \mathrm{dl})$, but did not exhibit common signs of chronic alcohol abuse. All heroin and control subjects tested negative for all other common drugs of abuse including cocaine, barbiturates, benzodiazepines, and phencyclidine.

\section{Sample Preparation}

Coronal sections measuring $2-3 \mathrm{~cm}$ were taken throughout the rostrocaudal extent of the basal ganglia. The nucleus accumbens (core and shell) was dissected as previously described (Bannon et al, 1992), flash frozen in isopentane cooled in liquid nitrogen, and stored at $-80^{\circ} \mathrm{C}$. Determination of the $\mathrm{pH}$ of an adjacent piece of cortex was used as an initial indicator of sample integrity, with all post-mortem samples exhibiting $\mathrm{pH}$ values within the desired range $(\mathrm{pH} \geqslant 6.1$; Kingsbury et al, 1995) (Table 1). RNA was extracted and characterized as previously described (Albertson et al, 2004). Briefly, frozen tissue was rapidly homogenized by Polytron in $10 \times$ w/v Tri Reagent (Sigma, St Louis, MO), RNA was chloroform/isopropanol extracted, precipitated, and reconstituted in sodium citrate (Ambion, Austin, TX). Contaminating DNA was eliminated using a Qiagen RNeasy Mini Kit (Valencia, CA). The Agilent 2100 Bioanalyzer (RNA Nano LabChip Kit, Agilent Technologies, Palo Alto, CA) was used to verify RNA abundance and sample quality (as indicated by a $2: 1$ ratio of $28 \mathrm{~S}$ to $18 \mathrm{~S}$ rRNA and the absence of DNA and degraded RNA species).

\section{Microarray Experiments and Data Analysis}

Affymetrix oligonucleotide arrays (Santa Clara, CA) were used in all studies. Initial examination of the glyceraldehyde-3-phosphate dehydrogenase (GAPDH) $3^{\prime} / 5^{\prime}$ ratios generated by cRNA hybridization to test chips provided an additional measure of RNA quality as well as a measure of the efficiency of the RT-PCR and in vitro transcription reactions. According to Affymetrix quality control parameters, this ratio should be $<3.0$ (see Table 1). For subsequent full-scale analysis, samples were hybridized to both human $\mathrm{u} 133 \mathrm{~A}$ and $\mathrm{u} 133 \mathrm{~B}$ arrays, representing over 39000 transcripts. All sample labeling, hybridization, and scanning followed the Affymetrix GeneChip ${ }^{\circledR}$ Expression Analysis Technical Manual (www.affymetrix.com). The complete absence in all subject samples of dopamine transporter and tyrosine hydroxylase transcripts (data not shown) supports the contention that nucleus accumbens mRNA was derived predominantly, if not exclusively, from cells intrinsic to this nucleus.

Data were analyzed with the Affymetrix Microarray Suite 5.0 software package as previously described (Albertson et al, 2004; Bannon et al, 2005). Images were scaled for signal intensity to account for any differences between hybridization efficiencies. Subjects were analyzed in pairs, comparing each heroin sample with its matched control. Significant differences between subject pairs were calculated using the Wilcoxon signed rank test $(p \leqslant 0.05)$; marginal calls were considered nonsignificant. For purposes of the present study, transcripts increased or decreased in the majority $(\geqslant 4$ of 7 ) of pairs were considered differentially expressed. Functional groups were created using annotation information provided by Affymetrix. A post hoc group-wise analysis of all genes identified on the microarray as residing within the category of synaptic transmission was performed with the non-parametric Mann-Whitney $U$-test $(p \leqslant 0.05)$.

\section{RT-PCR}

RNA from all subjects was used for verification of the microarray data. Reverse transcription (RT) was performed (Sensiscript RT Kit, Qiagen) with random hexamer primers, whereas subsequent PCR used sequence-specific primers 
Table I Study Subject Characteristics

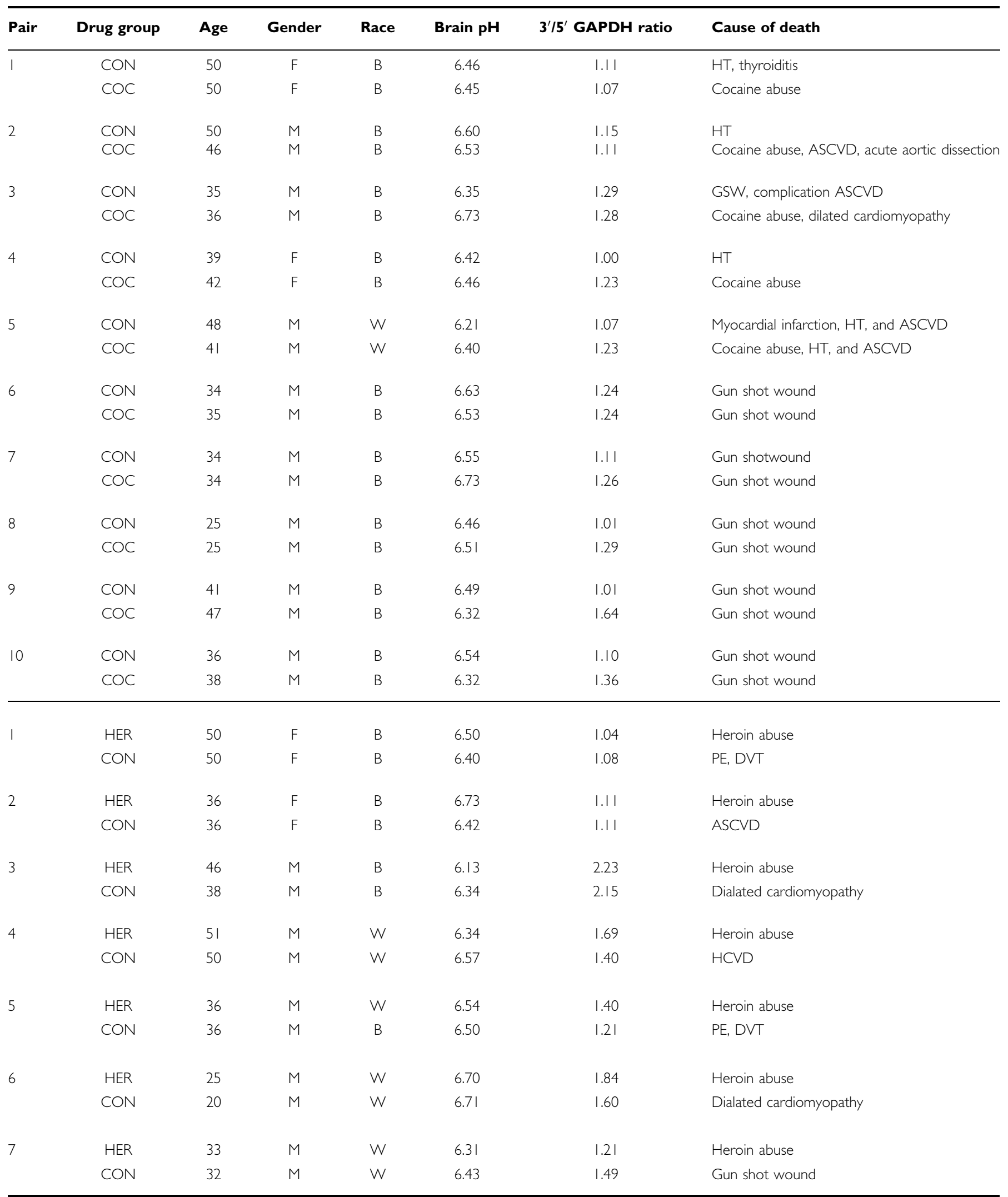

Drug abusers and control subjects were matched for demographic characteristics. Post-mortem brain samples exhibited similar pH and RNA integrity (reflected by GAPDH ratio). CON: control; COC: cocaine; HER: heroin; HT: hypertension; ASCVD: atherosclerotic cardiovascular disease; HCVD: hypertensive cardiovascular disease; PE: pulmonary embolism; DVT: deep vein thrombosis. The cocaine cohort and matched controls were part of a previously published study (Albertson et al, 2004). 
(amplicons: synaptogyrin 3 (SYNGR3) 1651-1849, synaptotagmin 1a (SYT1) 2098-2171, synapsin 2b (SYN2b) 3258-3453, synaptic vesicle protein 2A (SV2a) 2339-2410, prodynorphin (PDYN) $2265-2342$, and $\beta$-actin 1396-1578 or 2366-2631). PCR was performed in the LightCycler version 3.3 with the Qiagen SYBR Green PCR Kit (Roche, Indianapolis, IN) as described previously (Albertson et al, 2004). Equivalent amounts of RNA from each subject were pooled to create standard curves (input RNA 1-16 ng) that were assayed in parallel with replicate samples $(5 \mathrm{ng}$ RNA) from individual subjects. A linear standard curve was generated and all samples fell within the range of the curve. For sample normalization, individual transcript values were divided by the subject's $\beta$-actin values determined using the same RT reaction. $\beta$-Actin transcript levels did not differ between heroin abusers and control subjects, as determined by either RT-PCR $(p=0.85)$ or microarray $(p=0.10)$. Differences in transcript abundance between heroin abusers and matched controls were assessed by Wilcoxon signed rank tests.

\section{RESULTS}

\section{Overview of Sample Characterization and Microarray Data}

The integrity of the human post-mortem brain samples used in this study was evident from appropriate tissue $\mathrm{pH}$ values (Table 1), and the quality of RNA extracted from these samples was confirmed using spectrophotometric and electropherographic analyses (data not shown). Furthermore, the appropriately low $3^{\prime} / 5^{\prime}$ GAPDH ratios obtained by microarray analysis (Table 1) reflected both the quality of input RNA and the efficiency of the RT-PCR and in vitro transcription reactions used to generate cRNAs for microarray hybridizations (for more details, see Materials and methods).

Following sample hybridization to human u133A and u133B microarrays (representing over 39000 transcripts) and data analysis as previously described (Albertson et al, 2004; Bannon et al, 2005), it was determined that $49.7 \%$ of the transcripts represented on the arrays were expressed ('present') in the nucleus accumbens of all subjects. Global visualization of transcript abundances, as determined in the present study and our previous cocaine study (Albertson et al, 2004), revealed that most transcripts did not differ significantly in abundance between heroin abusers (Figure 1a) or cocaine abusers (Figure 1b) and their matched drug-free controls (represented as drug/control signal log ratio). Pairwise analyses between heroin abusers and their matched controls revealed that a total of 1050 transcripts were differentially expressed across the majority of subject pairs (for a complete list of these transcripts, see Supplementary Table 1). Those transcripts that are annotated encode proteins thought to be involved in a wide variety of cellular processes including synaptic transmission, structural organization, metabolism, energy pathways, apoptotic processes, stress and immune responses, transcriptional regulation, and other processes. Within these broad functional categories, however, few patterns of gene expression changes were evident.
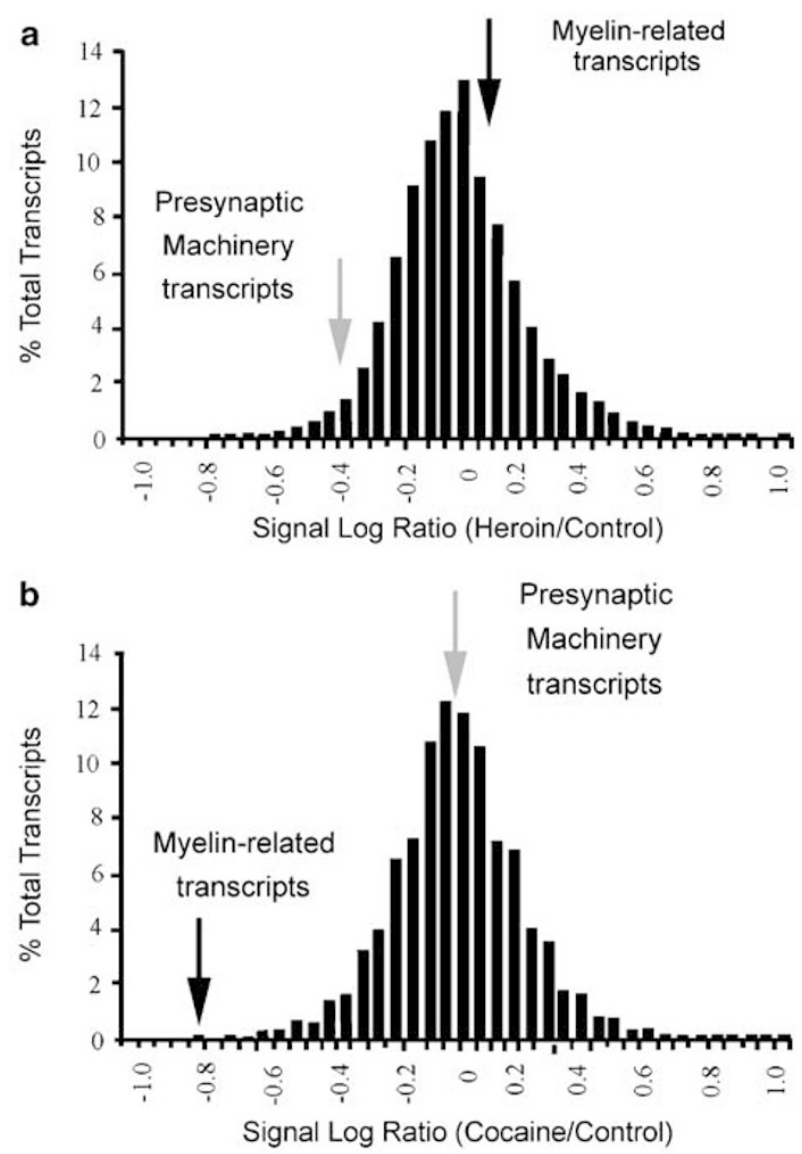

Figure I Altered transcript abundance in the nucleus accumbens of human cocaine and heroin abusers. The signal log ratio (log base 2) distribution of all transcripts detected in the majority of subject pairs was plotted after binning averages into groups of 0.05 (a:n=18 055, b: $n=17$ 688). Values falling to the left of zero indicate a downregulation of transcript abundance in drug abusers, whereas those to the right of zero are indicative of increases. The mean signal log ratio of myelin-related transcripts (MBP, MOBP, and PLP) for each study was plotted in relation to the normal distribution of all present transcripts, and is represented by black arrows (a:mean $=0.13$; b:mean $=-0.8 \mathrm{I})$. The mean signal log ratio for all presynaptic machinery transcripts (listed in Figure 2a) is represented by gray arrows (a:mean $=-0.39 ; \mathrm{b}:$ mean $=-0.00 \mathrm{I}$ ). Note that the majority of transcripts are unchanged in either heroin abusers (a) or cocaine abusers (b), and that changes in myelin-related and presynaptic machinery transcripts are drug specific.

\section{Myelin-Related Transcripts}

In our previous analysis of chronic cocaine abusers (Albertson et al, 2004), we had identified a significant downregulation of multiple transcripts derived from the myelin-related genes MBP, MOBP, and PLP (see Figure 1b), a finding confirmed by RT-PCR and immunohistochemical experiments. In the present study, examination of human heroin abusers failed to reveal any significant change in the expression of this group of genes (Figure 1a). There was no directional trend toward a change in the abundance of any of these myelin-related transcripts individually (data not shown), suggesting that the effects seen on myelin-related gene expression were selective for cocaine abusers in comparison to heroin abusers. 


\section{Presynaptic Machinery Genes}

Perhaps the most striking finding arising from the microarray analysis of the nucleus accumbens of the heroin cohort was the decreased abundance of a number of transcripts encoding presynaptic machinery proteins (Figure 1a). Genes encoding proteins involved in multiple aspects of neurotransmitter release, including vesicle storage, release, and recycling, were impacted, as illustrated in detail in Figure 2a. No corresponding downregulation of gene expression was seen in cocaine abusers (Figures $1 \mathrm{~b}$ and 2a), supporting the specificity of this microarray finding.

In subsequent experiments, we employed quantitative real-time PCR to determine the abundance of four representative transcripts (namely synapsin $2 \mathrm{~b}$, synaptotagmin 1a, synaptic vesicle protein $2 \mathrm{a}$, and synaptogyrin 3 ; Figure $2 \mathrm{~b}$ ). When examined as a group, the abundance of these four transcripts was significantly decreased in heroin subjects as compared to matched controls $(Z=-3.758$, $p=0.001$, Wilcoxon signed rank test), and the $\log 2$ ratios for each subject pair as determined by microarray and
RT-PCR were significantly correlated ( $p=0.049$, Pearson's correlation). When considering each transcript separately, however, a significant correlation between pairwise microarray and PCR data was seen only in the case of synaptogyrin $3(p=0.040)$, with correlations for the other transcripts failing to reach significance. Nevertheless, in spite of the limited power afforded by the modest sample size, PCR analysis did validate the central microarray finding of heroin-related decreases in transcripts encoding synaptogyrin $3 \quad(Z=-2.213, \quad p=0.027)$, synapsin $2 \mathrm{~b}$ $(Z=-1.859, p=0.046)$, and synaptic vesicle protein $2 \mathrm{a}$ $(Z=-2.197, p=0.028)$ (Figure $2 b)$. In the case of synaptotagmin $1 \mathrm{a}$, the decreased transcript abundance seen in five of seven subject pairs did not achieve statistical significance $(Z=-1.532, p=0.128)$.

\section{General Comparison of Cocaine and Heroin Data Sets}

In contrast to the relatively small list of transcripts significantly altered in the nucleus accumbens of cocaine abusers (Albertson et al, 2004), 1050 transcripts were

\begin{tabular}{|c|c|c|c|c|c|c|c|c|c|c|c|c|}
\hline \multirow{2}{*}{$\begin{array}{l}\text { a } \\
\text { Gene Symbol }\end{array}$} & \multirow[b]{2}{*}{ Gene Name } & \multirow{2}{*}{$\begin{array}{l}\text { Presynaptic } \\
\text { Process } \\
\end{array}$} & \multirow{2}{*}{$\begin{array}{c}\text { Affymetrix } \\
\text { Probe ID }\end{array}$} & \multirow{2}{*}{$\begin{array}{l}\text { Heroin SLR } \\
\text { Median }\end{array}$} & \multicolumn{7}{|c|}{ Heroin/Control SLR (log2 ratio) } & \multirow{2}{*}{$\begin{array}{c}\text { Cocaine SLR } \\
\text { Median }\end{array}$} \\
\hline & & & & & 1 & 2 & 3 & 4 & 5 & 6 & 7 & \\
\hline SNAP25 & synaptosomal-associated protein $25 \mathrm{kDa}$ & 1 & 202507 & -0.42 & .0 .68 & -1.02 & 0.30 & 0.76 & -0.31 & -0.42 & -0.51 & -0.02 \\
\hline STXBP6 & syntaxin binding protein 6 (amysin) & 1 & 220994 & -1.20 & -1.20 & -2.83 & -1.76 & 0.11 & 0.19 & -1.25 & -0.27 & -0.12 \\
\hline STXBPG & syntaxin binding protein 6 (amysin) & 1 & 230560 & -0.43 & -0.50 & -0.84 & .0 .08 & .0 .33 & -0.27 & -1.31 & -0.43 & -0.06 \\
\hline AMPH & amphiphysin & 2 & 205257 & -0.58 & -0.59 & -0.58 & 0.14 & 0.26 & -0.89 & -0.68 & 0.02 & -0.01 \\
\hline PLDN & pallidin & 2 & 224883 & -0.54 & -1.30 & -1.57 & 0.27 & -1.25 & -0.54 & -0.53 & 0.17 & .0 .02 \\
\hline SYN2a & synapsin Ila & 3 & 210247 & .0 .43 & .0 .23 & .0 .43 & -0.18 & .0 .52 & -0.70 & -0.45 & 0.22 & 0.08 \\
\hline SYN2b & synapsin Ilb & 3 & 229039 & -0.52 & -0.63 & $\cdot 0.60$ & 0.16 & 0.27 & -0.52 & -0.73 & 0.06 & 0.04 \\
\hline SYT1 & synaptotagmin I & 4 & 203998 & -0.59 & -1.67 & -0.59 & 0.69 & 1.17 & -1.00 & -1.16 & 0.31 & 0.15 \\
\hline STXBP1 & syntaxin binding protein 1 (munc 18-1) & 1 & 202260 & -0.33 & -0.43 & -0.33 & 0.18 & 0.13 & -0.36 & -0.33 & -0.12 & 0.04 \\
\hline SYNGR3 & synaptogyrin 3 & 5 & 205691 & -0.31 & -0.72 & -0.38 & 0.19 & -0.17 & -0.31 & -0.59 & -0.10 & 0.09 \\
\hline$S V 2 a^{*}$ & synaptic vesicle protein $2 a$ & 4 & 203069 & .0 .24 & -0.59 & 0.00 & 0.01 & .0 .24 & -0.30 & -0.44 & 0.04 & 0.21 \\
\hline$V t i 1 b^{*}$ & Vti1b & 2 & 225928 & .0 .24 & .0 .24 & .0 .36 & 0.13 & -0.08 & .0 .38 & -0.71 & 0.19 & -0.13 \\
\hline
\end{tabular}

b
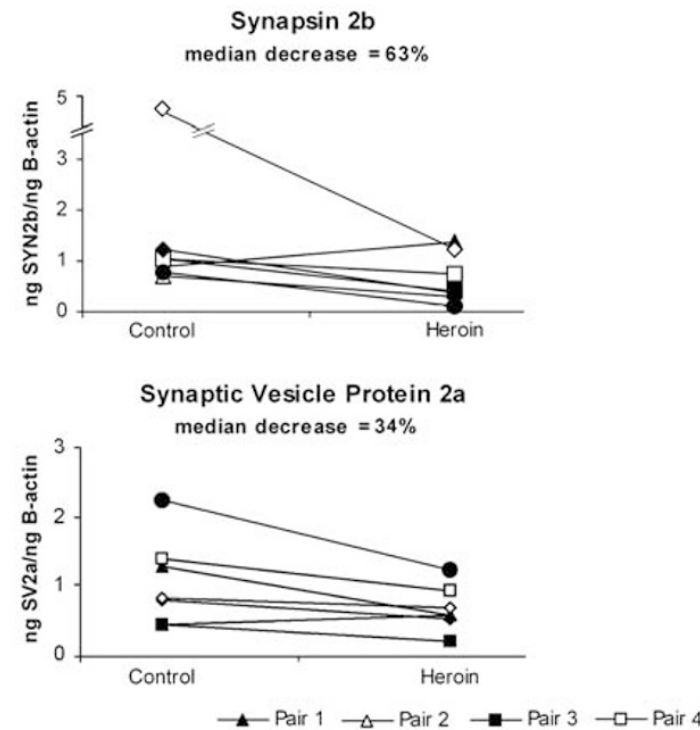
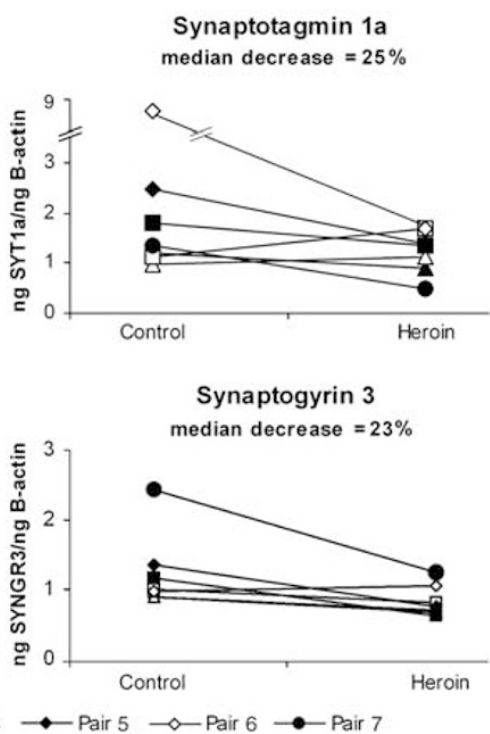

Figure 2 Decreased expression of presynaptic machinery genes in human heroin abusers. (a) Specific presynaptic machinery genes, their putative functions, and Affymetrix probe ID numbers are listed. Median and individual signal log ratios for the seven heroin-control pairs are shown (as are median SLR from the cocaine study as a comparison). (b) Quantitative real-time RT-PCR was used to determine the abundance of four representative transcripts (synapsin 2b, synaptotagmin Ia, synaptic vesicle protein $2 \mathrm{a}$, and synaptogyrin 3 ). All transcript levels were divided by $\beta$-actin levels, which did not differ between groups (see Materials and methods). Significant heroin-related decreases in transcript levels were validated in the case of synapsin $2 b(p=0.046)$, synaptic vesicle protein $2 a(p=0.028)$, synaptogyrin $3(p=0.027)$, but not synaptotagmin Ia $(p=0.128)$. Median percent decrease across all subject pairs is also shown for each of the four transcripts. 
significantly changed in the majority of heroin cohort subject pairs (Supplementary Table 1). When the lists of changed transcripts from both drug-abusing cohorts were compared directly, only 25 out of the approximately 39000 possible transcripts were differentially expressed in both data sets, with 10 of these changed in opposite directions (Table 2). As is common with microarray studies, many of the transcripts within this overlap list are insufficiently annotated, although a few genes have been previously associated in some manner with drug abuse (see Discussion). To date, we have not further investigated the gene expression changes reported in Table 2, with the exception of the opioid peptide-encoding prodynorphin transcript, which was found to be increased in cocaine abusers and decreased in heroin abusers by RT-PCR (median cocaine expression $=149 \%$ of control; median heroin expression $=66 \%$ of control), with a significant correlation between the PCR and microarray data $(r=0.769 ; p=0.001)$.

\section{DISCUSSION}

High-throughput microarray technology makes it possible to simultaneously interrogate tens of thousands of transcripts in a discovery-driven process that should provide novel insights into disease processes. In this study, we have profiled the changes in gene expression in the nucleus accumbens of human heroin abusers relative to matched controls, and found nearly 10 times the number of genes changed compared to a cocaine cohort we have analyzed in an identical manner (Albertson et al, 2004). We have directly compared data from the two groups of chronic drug abusers. Transcript changes specific to either the heroin- or cocaine-abusing group could be due to the unique sites and mechanisms of action of these drugs. Transcript changes common to both cohorts of drug abusers could reflect excessive dopamine neurotransmission in the nucleus accumbens, as this is thought to be a common mechanism of all drugs of abuse.

The most robust and consistent finding from our previous cocaine study was a significant downregulation of myelin-related genes, as well as an apparent loss of MBPimmunoreactive oligodendrocytes (Albertson et al, 2004). At that time, we put forth the hypothesis that these cocainerelated expression changes could be due to an effect of excess dopamine in the nucleus accumbens, given the inhibitory effect of dopamine on the maturation of oligodendrocyte progenitors (Bongarzone et al, 1998; Howard et al, 1998). Because drugs of abuse are generally believed to facilitate nucleus accumbens dopamine release, according to this hypothesis myelin-related gene expression should also be decreased in our cohort of heroin abusers. On the

Table 2 Genes Significantly Altered in Both the Heroin and Cocaine Abusers

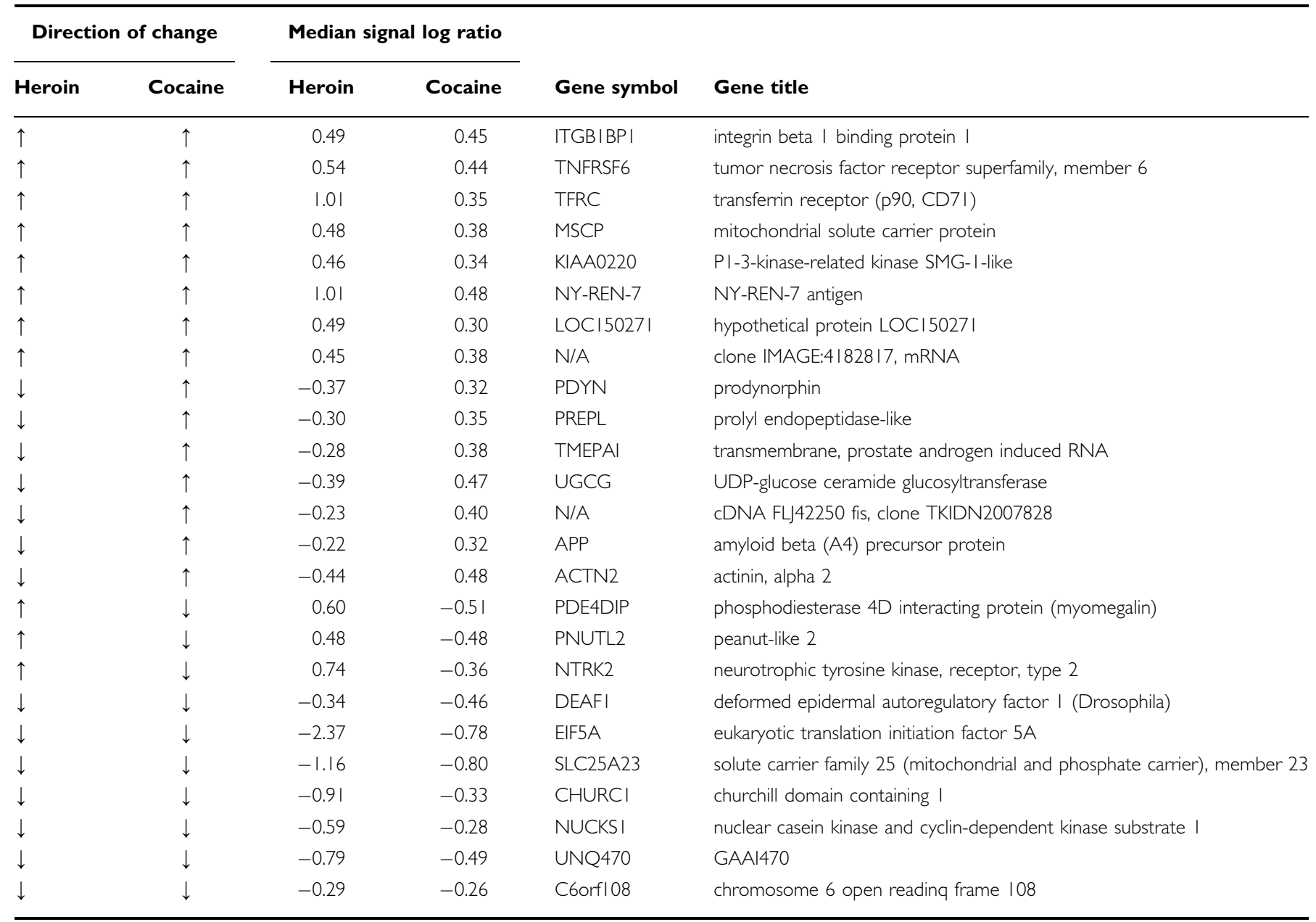


contrary, we found no decrease (nor even a trend toward a decrease) in any myelin-related transcript in this group (Figure 1a). On the surface, these data seem to argue against our original 'excess dopamine' hypothesis as a plausible explanation for the cocaine study myelin findings. In fact, although some investigators have reported that heroin selfadministration increases dopamine release in the nucleus accumbens (Wise et al, 1995; Xi et al, 1998), other data strongly indicate that, in contrast to cocaine, heroin does not influence dopamine outflow (Hemby et al, 1995, 1999; Smith et al, 2006). In any case, there is very clear evidence for a powerful dopamine-independent reward mechanism in the nucleus accumbens that mediates heroin self-administration (Ettenberg et al, 1982; Pettit et al, 1984). Thus, differences in the dopamine-releasing and other neurochemical effects of heroin could mediate differences we found in the profile of gene expression in the nucleus accumbens, including differential effects on myelin-related and presynaptic machinery genes.

In our heroin cohort, we found significant decreases in the expression of numerous genes encoding presynaptic machinery proteins involved in processes related to neurotransmitter release. Synaptotagmin 1 is located on synaptic vesicles and is thought to act as a calcium sensor for fast neurotransmitter release (Sudhof, 2004). SNAP25 participates in the SNARE complex mediating vesicle exocytosis (Sudhof, 2004). Munc 18-1 controls synaptic fusion by binding syntaxin, preventing SNARE formation until its release (Sudhof, 2004). Synapsin 2a and 2b are vesicular proteins required to maintain normal amounts of vesicles. Amphiphysin is a component of the presynaptic clathrin-coated intermediate formed during vesicular recycling (Slepnev and De Camilli, 2000). Pallidin, which is located on early endosomes and is known to bind syntaxin 13 on the vesicle surface, facilitates docking and fusion during recycling (Huang et al, 1999). Amysin (for which two transcripts were downregulated) regulates the assembly of the SNARE composite by forming stable complexes with the synaptic t-SNAREs syntaxin 1 and SNAP25, and inhibits exocytosis by interfering with synaptobrevin (Scales et al, 2002). Synaptogyrin 3 is a recently discovered brain-specific vesicular protein of unknown function (Belizaire et al, 2004). After identification of the many changes in this functional group by pairwise analysis, we conducted a post hoc group-wise analysis of other release-related genes represented on the microarray. Significant decreases in transcript abundance of both Vtilb, a vesicular SNARE protein functioning in endosomal recycling (Jahn et al, 2003), and SV2a, an essential protein implicated in the transport of calcium into vesicles (Sudhof, 2004), were identified in this manner. Subsequent quantitative PCR experiments validated the microarray findings for three of four transcripts tested. The downregulation of so many genes encoding known SNARE proteins, vesicular proteins, and recycling proteins implies a synaptic dysfunction within the brains of human heroin abusers.

Until relatively recently, gene expression studies have been limited to individual candidate genes and, to our knowledge, effects of heroin on presynaptic release proteins have not been reported. In a rat model utilizing morphine pellet implantation, striatal expression of synapsin $2 \mathrm{a}$ was found to be increased after several days of continuous, passive drug exposure. It is conceivable that the downregulation of presynaptic protein gene transcripts seen in the nucleus accumbens of our chronic heroin abusers is a compensatory response to an acute opiate-mediated upregulation. Differences in the method, pattern, and length of drug exposure (not to mention potential species differences) highlight the importance of pursuing complementary studies in both human material and animal or cell culture models.

It has been suggested that expression of the vesicular protein synapsin is particularly sensitive to disorders of cognition and mood (Vawter et al, 2002), as evidenced by decreased abundances in human post-mortem brain studies investigating bipolar disorder, schizophrenia, and Alzheimer's disease (Ho et al, 2001; Mirnics et al, 2000; Vawter et al, 2002). Although our study focuses solely on the nucleus accumbens and therefore cannot speak to more global reductions in synapsin 2 expression, the cognitive deficits documented in human heroin abusers (Ornstein et al, 2000; Pau et al, 2002), in combination with our synapsin data, could lend support to this notion.

Interestingly, when we directly compared the data from heroin abusers with our previous study on gene expression changes in the nucleus accumbens of human cocaine abusers, few transcripts were seen in common. To our knowledge, only three of these transcripts are known to be regulated by, or involved in the signaling of, heroin or cocaine. None fall within the group of transcripts downregulated in both drug-abusing cohorts. Within the group of transcripts increased in both cocaine and heroin abusers was tumor necrosis factor receptor superfamily member 6 , encoding the proapoptotic receptor FAS (Table 2). Chronic heroin and morphine administration elicits a similar effect in rodent brain to what we report in heroin abusers (Boronat et al, 2001; Garcia-Fuster et al, 2003; Yin et al, 1999). Although this is the first report of FAS mRNA upregulation by cocaine, this pathway is upregulated by methamphetamine (Jayanthi et al, 2005).

Nearly one-half of the transcripts affected in both drug-abusing cohorts were actually changed in opposite directions. As an example, the transcript encoding the endogenous opioid peptide prodynorphin (PDYN) was differentially regulated between groups. Both microarray analysis and PCR revealed that PDYN mRNA levels were increased in cocaine subjects but decreased in heroin abusers. Cocaine-induced increases in PDYN levels are well documented (Hurd et al, 1999). Several days of morphine treatment also increases PDYN (Gerfen et al, 1990; Turchan et al, 1997), although the effects of longer exposure are not known. Dynorphin attenuates cocaine-induced increases in dopamine levels and has been hypothesized to act via $\kappa$ opioid receptors to modulate dopamine system responses to stimulant administration (Kreek et al, 2005). Dynorphin peptides are also likely involved in adaptations to opiate abuse, as they affect $\mu$ opioid receptor function and indirectly dopamine neurotransmission (Kreek et al, 2005). It is possible that the local effects of heroin on the accumbens opioid receptors supercede the common effects of dopamine to elicit the differences in PDYN gene expression seen in cocaine and heroin abusers. Another example of differential regulation is the neurotrophin receptor NTRK2 (also known as TrkB), which was identified 
by microarray analysis as significantly upregulated in heroin abusers but downregulated in cocaine-abusing subjects (Table 2). In rodents, cocaine's effects on NTRK2 expression differ markedly depending upon the length of drug administration and withdrawal (Freeman et al, 2003; Lucas et al, 2003; Toda et al, 2002). Although heroin effects of NTRK2 expression have not been reported, it is interesting to note that morphine increases autophosphorylation of this receptor, and its activation plays a critical role in opiate-induced analgesia (Freeman et al, 2003; Lucas et al, 2003).

In conclusion, we report herein significant and distinctive changes in the profile of gene expression in the human nucleus accumbens associated with cocaine and heroin abuse. Documentation of the molecular correlates of addiction may ultimately suggest novel therapeutic strategies for the treatment of drug abuse. To date, the focus of thinking about drugs of abuse has been on the commonality of mesolimbic reward pathway activation. These data suggest that the molecular consequences of heroin and cocaine abuse are largely unique despite some common effects on dopamine in the nucleus accumbens, and that a re-examination of our current assumptions of the importance of common mechanisms in all addictive substances is warranted.

\section{ACKNOWLEDGEMENTS}

We thank Dr Susan Land and Dan Lott of the Wayne State University Applied Genomics Technology Center for technical assistance. This work was supported by NIDA Grant DA06470.

\section{REFERENCES}

Albertson DN, Pruetz B, Schmidt CJ, Kuhn DM, Kapatos G, Bannon MJ (2004). Gene expression profile of the nucleus accumbens of human cocaine abusers: evidence for dysregulation of myelin. J Neurochem 88: 1211-1219.

Bannon MJ, Kapatos G, Albertson DN (2005). Gene expression profiling in the brains of human cocaine abusers. Addict Biol 10: $119-126$

Bannon MJ, Poosch MS, Haverstick DM, Mandal A, Xue IC, Shibata K et al (1992). Preprotachykinin gene expression in the human basal ganglia: characterization of mRNAs and premRNAs produced by alternate RNA splicing. Brain Res Mol Brain Res 12: 225-231.

Bartzokis G, Beckson M, Hance DB, Lu PH, Foster JA, Mintz J et al (1999a). Magnetic resonance imaging evidence of 'silent' cerebrovascular toxicity in cocaine dependence. Biol Psychiat 45: 1203-1211.

Bartzokis G, Beckson M, Lu PH, Edwards N, Bridge P, Mintz J (2002). Brain maturation may be arrested in chronic cocaine addicts. Biol Psychiat 51: 605-611.

Bartzokis G, Goldstein IB, Hance DB, Beckson M, Shapiro D, Lu $\mathrm{PH}$ et al (1999b). The incidence of T2-weighted MR imaging signal abnormalities in the brain of cocaine-dependent patients is age-related and region-specific. Am J Neuroradiol 20: $1628-1635$.

Belizaire R, Komanduri C, Wooten K, Chen M, Thaller C, Janz R (2004). Characterization of synaptogyrin 3 as a new synaptic vesicle protein. J Comp Neurol 470: 266-281.

Bongarzone ER, Howard SG, Schonmann V, Campagnoni AT (1998). Identification of the dopamine D3 receptor in oligo- dendrocyte precursors: potential role in regulating differentiation and myelin formation. J Neurosci 18: 5344-5353.

Boronat MA, Garcia-Fuster MJ, Garcia-Sevilla JA (2001). Chronic morphine induces up-regulation of the pro-apoptotic Fas receptor and down-regulation of the anti-apoptotic Bcl-2 oncoprotein in rat brain. Br J Pharmacol 134: 1263-1270.

Chang L, Ernst T, Strickland T, Mehringer CM (1999). Gender effects on persistent cerebral metabolite changes in the frontal lobes of abstinent cocaine users. Am J Psychiat 156: 716-722.

Chang L, Mehringer CM, Ernst T, Melchor R, Myers H, Forney D et al (1997). Neurochemical alterations in asymptomatic abstinent cocaine users: a proton magnetic resonance spectroscopy study. Biol Psychiat 42: 1105-1114.

Ettenberg A, Pettit HO, Bloom FE, Koob GF (1982). Heroin and cocaine intravenous self-administration in rats: mediation by separate neural systems. Psychopharmacology (Berlin) 78: 204-209.

Freeman AY, Soghomonian JJ, Pierce RC (2003). Tyrosine kinase B and $C$ receptors in the neostriatum and nucleus accumbens are co-localized in enkephalin-positive and enkephalin-negative neuronal profiles and their expression is influenced by cocaine. Neuroscience 117: 147-156.

Garcia-Fuster MJ, Ferrer-Alcon M, Miralles A, Garcia-Sevilla JA (2003). Modulation of Fas receptor proteins and dynamin during opiate addiction and induction of opiate withdrawal in rat brain. Naunyn Schmiedebergs Arch Pharmacol 368: 421-431.

Gerfen CR, Engber TM, Mahan LC, Susel Z, Chase TN, Monsma FJ et al (1990). D1 and D2 dopamine receptor-regulated gene expression of striatonigral and striatopallidal neurons. Science 250: $1429-1432$

Hemby SE, Co C, Dworkin SI, Smith JE (1999). Synergistic elevations in nucleus accumbens extracellular dopamine concentrations during self-administration of cocaine/heroin combinations (Speedball) in rats. J Pharmacol Exp Ther 288: 274-280.

Hemby SE, Martin TJ, Co C, Dworkin SI, Smith JE (1995). The effects of intravenous heroin administration on extracellular nucleus accumbens dopamine concentrations as determined by in vivo microdialysis. J Pharmacol Exp Ther 273: 591-598.

Ho L, Guo Y, Spielman L, Petrescu O, Haroutunian V, Purohit D et al (2001). Altered expression of a-type but not b-type synapsin isoform in the brain of patients at high risk for Alzheimer's disease assessed by DNA microarray technique. Neurosci Lett 298: 191-194.

Howard S, Landry C, Fisher R, Bezouglaia O, Handley V, Campagnoni A (1998). Postnatal localization and morphogenesis of cells expressing the dopaminergic D2 receptor gene in rat brain: expression in non-neuronal cells. J Comp Neurol 391: 87-98.

Huang L, Kuo YM, Gitschier J (1999). The pallid gene encodes a novel, syntaxin 13-interacting protein involved in platelet storage pool deficiency. Nat Genet 23: 329-332.

Hurd YL, Svensson P, Ponten M (1999). The role of dopamine, dynorphin, and CART systems in the ventral striatum and amygdala in cocaine abuse. Ann NY Acad Sci 877: 499-506.

Jahn R, Lang T, Sudhof TC (2003). Membrane fusion. Cell 112: 519-533.

Jayanthi S, Deng X, Ladenheim B, McCoy MT, Cluster A, Cai NS et al (2005). Calcineurin/NFAT-induced up-regulation of the Fas ligand/Fas death pathway is involved in methamphetamineinduced neuronal apoptosis. Proc Natl Acad Sci USA 102: 868-873.

Kingsbury AE, Foster OJ, Nisbet AP, Cairns N, Bray L, Eve DJ et al (1995). Tissue $\mathrm{pH}$ as an indicator of mRNA preservation in human post-mortem brain. Brain Res Mol Brain Res 28: 311-318.

Kreek MJ, Bart G, Lilly C, LaForge KS, Nielsen DA (2005). Pharmacogenetics and human molecular genetics of opiate and cocaine addictions and their treatments. Pharmacol Rev 57: $1-26$ 
Lehrmann E, Oyler J, Vawter MP, Hyde TM, Kolachana B, Kleinman JE et al (2003). Transcriptional profiling in the human prefrontal cortex: evidence for two activational states associated with cocaine abuse. Pharmacogenomics J 3: 27-40.

Lewohl JM, Wang L, Miles MF, Zhang L, Dodd PR, Harris RA (2000). Gene expression in human alcoholism: microarray analysis of frontal cortex. Alcohol Clin Exp Res 24: 1873-1882.

Lim KO, Choi SJ, Pomara N, Wolkin A, Rotrosen JP (2002). Reduced frontal white matter integrity in cocaine dependence: a controlled diffusion tensor imaging study. Biol Psychiat 51: 890-895.

Lucas G, Hendolin P, Harkany T, Agerman K, Paratcha G, Holmgren $\mathrm{C}$ et al (2003). Neurotrophin-4 mediated TrkB activation reinforces morphine-induced analgesia. Nat Neurosci 6: 221-222.

Mayfield RD, Lewohl JM, Dodd PR, Herlihy A, Liu J, Harris RA (2002). Patterns of gene expression are altered in the frontal and motor cortices of human alcoholics. J Neurochem 81: 802-813.

Mirnics K, Middleton FA, Marquez A, Lewis DA, Levitt P (2000). Molecular characterization of schizophrenia viewed by microarray analysis of gene expression in prefrontal cortex. Neuron 28: $53-67$.

Ornstein TJ, Iddon JL, Baldacchino AM, Sahakian BJ, London M, Everitt BJ et al (2000). Profiles of cognitive dysfunction in chronic amphetamine and heroin abusers. Neuropsychopharmacology 23: 113-126.

Pau CW, Lee TM, Chan SF (2002). The impact of heroin on frontal executive functions. Arch Clin Neuropsychol 17: 663-670.

Pettit HO, Ettenberg A, Bloom FE, Koob GF (1984). Destruction of dopamine in the nucleus accumbens selectively attenuates cocaine but not heroin self-administration in rats. Psychopharmacology (Berlin) 84: 167-173.

Scales SJ, Hesser BA, Masuda ES, Scheller RH (2002). Amisyn, a novel syntaxin-binding protein that may regulate SNARE complex assembly. J Biol Chem 277: 28271-28279.
Slepnev VI, De Camilli P (2000). Accessory factors in clathrindependent synaptic vesicle endocytosis. Nat Rev Neurosci 1: 161-172.

Smith JE, Co C, Coller MD, Hemby SE, Martin TJ (2006). Selfadministered heroin and cocaine combinations in the rat: additive reinforcing effects-supra-additive effects on nucleus accumbens extracellular dopamine. Neuropsychopharmacology 31: $139-150$.

Sudhof TC (2004). The synaptic vesicle cycle. Annu Rev Neurosci 27: 509-547.

Tang WX, Fasulo WH, Mash DC, Hemby SE (2003). Molecular profiling of midbrain dopamine regions in cocaine overdose victims. J Neurochem 85: 911-924.

Toda S, McGinty JF, Kalivas PW (2002). Repeated cocaine administration alters the expression of genes in corticolimbic circuitry after a 3-week withdrawal: a DNA macroarray study. J Neurochem 82: 1290-1299.

Turchan J, Lason W, Budziszewska B, Przewlocka B (1997). Effects of single and repeated morphine administration on the prodynorphin, proenkephalin and dopamine D2 receptor gene expression in the mouse brain. Neuropeptides 31: 24-28.

Vawter MP, Thatcher L, Usen N, Hyde TM, Kleinman JE, Freed WJ (2002). Reduction of synapsin in the hippocampus of patients with bipolar disorder and schizophrenia. Mol Psychiat 7: $571-578$.

Wise RA, Leone P, Rivest R, Leeb K (1995). Elevations of nucleus accumbens dopamine and DOPAC levels during intravenous heroin self-administration. Synapse 21: 140-148.

Xi ZX, Fuller SA, Stein EA (1998). Dopamine release in the nucleus accumbens during heroin self-administration is modulated by kappa opioid receptors: an in vivo fast-cyclic voltammetry study. J Pharmacol Exp Ther 284: 151-161.

Yin D, Mufson RA, Wang R, Shi Y (1999). Fas-mediated cell death promoted by opioids. Nature 397: 218.

Supplementary Information accompanies the paper on the Neuropsychopharmacology website (http://www.nature.com/npp). 